\title{
The Ideological Conflict between Mainstream and Ethnospecific Agencies
}

\author{
Miranda Pinto and Lydia Sawicki
}

\begin{abstract}
This paper examines the conflict between ethnospecific immigrant serving organisations and so called "mainstream" organisations. The author argues that most of the criticisms raised against ethnospecific organisations are ideologically based and are meant to consolidate the positions of mainstream organisations. Through "neutral policies" such as fiscal restraint, ethnospecific agencies are increasingly peripherized in the service provision market. This piece concludes that attempts to resolve the conflict have only led to further and wider polarisation.
\end{abstract}

\section{Précis}

Cet article examine le conflit existant entre les organisations assurant des services ciblant des immigrants de groupes ethniques spécifiques (organisations "ethno-spécifiques") et les organisations dites "classiques". L'auteure développe une argumentation selon laquelle la majorité des critiques soulevées contre les organisations ethno-spécifiques sont orientées idéologiquement et visent exclusivement à consolider la position des organisations classiques. Par le biais de "mesures neutres", comme par exemple les restrictions fiscales, les agences ethno-spécifiques se voient de plus en plus repoussées à la périphérie du marchéde la diffusion des services. L'exposé se conclut sur le constat que toutes les tentatives visant d résorber ce conflit ont menéd une polarisation encore plus profonde et plus accusée des groupes en présence.

Miranda Pinto is Regional Director, Catholic Cross-Cultural Services, Toronto.

Lydia Sawicki is Project Coordinator, Centre for Refugee Studies, York University, Toronto.

The views expressed in this paper are those of the authors, not necessarily those of their institutions.
Immigrant and refugee settlement agencies service the largest percentage of the countries' new arrivals in the expanding and restructuring City of Toronto. Although little data exist on the inflow of newcomers to the city, the Immigration and Refugee Board (IRB) in Toronto finalised 2,363 claims up until the third quarter of $1996 .{ }^{1}$ With unquestionable personal sacrifice those involved in settlement agencies provide through the work they do a bridge between a wide array of distinct cultures, facilitating their introduction to the Toronto mosaic. For the purpose of this discussion, we describe two kinds of agencies that newcomers can access upon their arrival as polarised, that is, we see that new arrivals make a choice at this fork in the road of the settlement process between two opposing types of agencies.. Broadly speaking then, they decide between "mainstream" and "ethnospecific" immigrant integration agencies. These organisations are structurally different in scale of operation, role in organisational networking, levels of professionalism, and further, they have different funding sources and proportions, and therefore, they are ideologically-opposed.

The ideology that promotes these two very different goals, assimilation or acculturation, is key in the allocation of funding and in the promotion of certain settlement programs over others. When assimilation into the dominant Anglo-Saxon culture is the goal, then mainstream agencies are favoured for their largely Eurocentric philosophy (sometimes religious) and programs - meant to help absorb the immigrant into the dominant culture. Ethnospecific agencies in their philosophy and in their program design promote acculturation, the continuation of the original cultural identity in the long run and less intrusive adapta- tion services in the short. From these different ideological perspectives, mainstream and ethnospecific agencies enter into conflict with regard to the allocation of funding and with regard to who best offers settlement services within the decreasing fiscal budget. While under the pressure of servicing a rapidly-changing ethnic composition, and within the framework of fiscal constraint and restructuring, these agencies offer two very different types of modus operandi, different funding sources and different ideological positionings. As they compete for some of the same funds, nevertheless, one benefits over the other in the exchange. This discussion leads to the exposure of the ideological conflict between both the agencies and within the machinery of fiscal distribution.

Until the 1970s, most immigrants came from Europe. During the 1980s, in contrast, 63.5 percent of immigrants were socalled "visible minorities" and came from a Third World country (Samuel 1990). The 1990s have continued to see large numbers of African and Asians entering Canada with ethnospecific needs and two kinds of settlement agencies have risen to meet the changing needs of the arriving communities in Canada: mainstream and ethnospecific. An ever-evolving array of communities test the refugee and immigrant settlement infrastructure with very specific needs and goals that range from language, employment, housing, health and those that rise from Canadian racial discrimination.

Immigrants and refugees require culturally-sensitive, integrated programs in order to achieve their goals quickly and effectively in the underfunded settlement process and come through with some sense of identity at the end of the day. Funding restraints ensure that shorter and shorter adap- 
tation periods occur as immigrants and refugees are expected to be almost instantly self-sufficient, both socially and economically, and well-integrated into Canadian society. In order best to address evolving immigrant and refugee needs, settlement agencies have varying approaches in their program design that accommodate cultural differences and the desperate need for an integrated array of services.

In order to address the conflict arising from the ideological differences between mainstream and ethnospecific agencies in Toronto, this paper begins by discussing the structural differences between the two categories of agencies in terms of size, programmatic and operational characteristics. Next, a comparison of funding sources and proportions is made in order to see where opportunities for loyalties and oppositions can be found in collaborative efforts. This exercise leads us to conclude how ideological differences are at the root of the conflict between these two types of agencies and how the ideological conflict underpins a larger debate about the duplication of services, collaboration between agencies and the long-term goals of assimilation or acculturation.

The structural differences between mainstream and ethnospecific agencies in terms of size, programmatic and operational characteristics are key to our discussion because these specifics establish power differentials in the service provision arena. Mainstream agencies have the advantage of having been longer in the arena and have built up larger agencies that are able to fund a wider array of integrated programs, with superior levels of professionalism. Ethnospecific agencies rise to meet particular settlement needs as they come up and in order to offer culturally-appropriate services, less developed levels of professionalism are prevalent. It is because these agencies possess different strengths that collaboration is a solution to some aspects of the conflict. While new Canadians can potentially access culturally-sensitive counselling and culturally-appropriate programs from ethnospecific agencies, they can also access integrated language, job skills programs and highly-trained professionals. But as funding competition mounts as the result of shrinking budgets and ideologically-backed restructuring, tension around collaborative efforts is becoming the subject of much discussion.

A comparison of funding sources and allocations between the two categories of agencies shows where loyalties and confrontations are founded in the conflict mounting in the service provision arena. Mainstream agencies are more successful in securing larger federal and provincial funding because they have more experience and leverage in offering competitively-integrated programs, often through collaboration with the ethnospecific agencies themselves. These collaborative efforts are marked by tension as a result of the agencies' need to firstly, protect the leverage achieved to date, and secondly, meet the conflicting demands for collaboration and non-duplication of services. The restructuring of the service provision arena requires all agencies to create innovative solutions that require less and less of the shrinking budget as they address growing and changing immigrant and refugee needs. Mainstream agencies not only service large numbers of new Canadians but they also often attend to the needs of the growing numbers of the country's poor, while scrambling to meet the requirements of government and private funders.

Ethnospecific agencies, on the other hand, feel the impact of funding adjustments and shrinking even more acutely from a disadvantaged position with less structural flexibility and capacity, less experience in the competition and relatively higher costs due to these same characteristics. Further, ethnospecific agencies must also find the larger percentage of their funding from private sources within communities that are themselves usually suffering more severely in the midst of fiscal restraint. At the end of the day, collaborative efforts are more necessary because of government funding de- mands that these efforts be made, and because the agencies' differing characteristics necessitate collaboration in order to provide the services that new Canadians require upon arrival. The needs must be met and in Canada, NGOs are the only providers of services to newcomers during what is a long integration period.

This analysis leads us to conclude that ideological differences are at the roat of the conflict between these two types of agencies because the agencies must structurally, programmatically, and ideologically define their longterm goals of assimilation or acculturation. Funding sources back or challenge the agencies' long-term goals and so far, the restructuring balance sheet has the final word in the conflict. More discussion in the service provision arena must occur in order to address more purposefully the growing levels of tension between the agencies, cries of overlapped service spending and evolving demands for collaboration. We hope that this paper, if nothing else, opens the discussion about the conflict between mainstream and ethnospecific agencies to those involved in those agencies themselves, academics who focus on immigrant and refugee settlement, and government funding agencies.

\section{Notes}

1. "Country of Persecution Analysis Report," Standards Analysis and Monitoring Committee, Immigration Refugee Board, Third Quarter 1996.

\section{Bibliography}

Burnaby, Barbara. 1996. "Coordinating Settlement Services: Why Is It So Difficult?" In Refugee Policy: Canada and the United States, edited by Howard Adelman. Toronto: York Lanes Press.

Gorman, Robert F. 1993. "Moving Along: The Odyssey of Refugee Resettlement." In Mitigating Misery. Maryland: University Press of America.

Heipel, Robert R. 1991. "Refugee Resettlement in a Canadian City: An Overview and Assessment," In Refugee Policy: Canada and the United States, edited by Howard Adelman. Toronto: York Lanes Press. 